\title{
Functional Movement Screening Tests for the Prediction of Injuries in Volleyball: A Qualitative Study
}

\author{
${ }^{1}$ Seyed Majid Tabatabaei ${ }^{*}{ }^{1}$ Hassan Daneshmandi, ${ }^{1}$ Ali Asghar Norasteh, ${ }^{2}$ Hamid Sharif Nia \\ ${ }^{1}$ Department of Sport Injuries and Corrective Exercises, Faculty of Sport Sciences, University of Guilan, Rasht, Iran. \\ ${ }^{2}$ School of Nursing and Midwifery, Mazandaran University of Medical Sciences, Sari, Iran.
}

\begin{abstract}
Background. There is little evidence to support the comprehensiveness of FMS in sports populations to predict injuries. Ignoring rapid decelerations and high eccentric forces which may be characteristics of high risk for injury are evident in these tests. With this in mind, it seems logical to use tests to assess the performance of athletes so as to evaluate speed components as well as to identify the potential risk factors for injury. This can be a good complement to FMS. Objectives. This study aimed to identify functional movement screening tests to predict injuries in volleyball. Methods. In this descriptive study, 20 high-level experts in volleyball were selected through purposive sampling. The data were collected in 2017 through semi-structured interviews and field notes. The interview transcripts were encoded using MAXQDA10 software ${ }^{\circ}$. To extract the categories and subjects, the thematic analysis approach was used. Results. In the first analysis process, the initial codes were extracted and finally, 38 of the 82 existing potential tests were identified. Then, after various stages of determining the validity and reliability of 12 tests - deep squat, inline lunge, trunk stability push up, rotary stability, shoulder mobility, triple hop for distance, hexagon, lateral lunge, triple jump for distance, sidearm medicine ball throw, closed kinetic chain upper extremity and squat jump-were identified for inclusion in this tool. Conclusions. Based on the results of the interviews, it could be concluded that the interviewees' choices were based more on the tests' similarity with the type of movement patterns and performance capabilities in volleyball and considering the anatomical areas prone to injury as well.
\end{abstract}

KEY WORDS: Functional Movement Screening, FMS Test, Volleyball, Injury Prediction, Qualitative Study.

\section{INTRODUCTION}

Movement is at the core of early growth and development perspective of humans, and it remains the central theme of an individual's overall life. As for exercise professionals, they promote movement, but as a group, they don't have standard screenings for risk factors associated with movement-based activities. As for rehabilitation professionals, they do not use a grading scale or standard for whole movement patterns. They measure the movement parts and assume those whose movements can be predicted. The screens and assessments now in use are not comprehensive, and they are impairment-based, performance-based or activity-specific (1)

While researchers have a common bias to study movement quantities, because they are clear and fit into numeric models, studying and measuring quality can be complicated. The evolution of recent exercise and rehabilitation has gone unchecked for quality because of this bias.

*. Corresponding Author:

Seyed Majid Tabatabaei

E-mail: majid.tabatabaea@yahoo.com 
In scientific research, both qualitative and quantitative specs need to be represented and considered continually. In this regard, the tools must be designed to be feasible to use and allow researchers to oppose the subjectivities that are often attributable to their experience and expertise and to the quantitative nature of the researchers' bias and dependence (2)

Researchers have always been instrumental in identifying risk factors and developing preventive strategies for injury and screening. Screening is done for a variety of purposes, and one of these goals in sports science, which is also very important, is the prevention of athlete injuries. Screening as a precursor to injury plays a very important role in developing preventive strategies for athletic injuries (3). This process can also be used to help prevent injury by identifying the functional defects and the abnormalities associated with the intended sport (4).

In line with this goal, Gray Cook et al. developed Functional Movement Screening (FMS) to identify individuals who have compensatory movement patterns in their kinetic chains. FMS consists of seven functional tests, which require a balance between mobility and stability. These tests include the deep squat, hurdle step, inline lunge, active straight leg raise, shoulder mobility, rotary stability and trunk stability push up. However, one aspect that the FMS does not address is a screening test at dynamic speed. When these tests are considered collectively, they are not reflective of the dynamic actions involved in many sports, neglecting rapid decelerations and high eccentric forces that may be a characteristic of high injury risk (5).

A major limitation of FMS is the absence of dynamic movements performed at high speed, which are inherent in the sport. Thus the FMS cannot be anticipated to fully represent the movement patterns achieved in a sport. This was found by Parchmann et al. (2011), who compared FMS and 1RM back squat and their correlation with 10/20 m sprint, jump height and agility t-test times in 25 NCAA division 1 golfers. The lack of correlation between FMS and these performance tests indicates that FMS has poor ability to predict physical performance measures of acceleration, power, and agility, especially when compared to maximal lower body strength (6). However, due to increased research on FMS and its lack of relationship with performance measures (7), additional assessments may provide further supporting evidence to complete the screening process.

The screening process in many countries takes place during pre-season exercises in several advanced sports (8). Pre-season information can be important for identifying the athletes who are at risk of injury. Dallinga et al. argued that the development of a screening tool can help to predict injury. They also said that screening tools should be of low cost, simple and generalizable on a wider scale in both laboratory and field settings. They used a research and survey strategy at the start of the development of the screening tool, which included reviewing articles from 1966 to September 2011. Of the 128 existing papers, only 23 articles had the full inclusion criteria for review. The literature review helped in determining the effective performance tests in predicting injury. Their findings showed that most screening tools were used to predict specific types of injuries, such as ACL injuries, ankle sprain or hamstring injuries, rather than a series of different injuries in a particular sport (9).

Looking at the literature on the screening of functional movement, it can be seen that this tool has been developed in some sports such as football (10), gymnastics (11), Australian football (12) and dance (13). Based on the literature, it can be concluded that the importance of functional screening movement in sports is well understood, but more research is needed in this field. Volleyball is assumed to be a safe sport compared to other team sports, such as football, handball and basketball, where frequent tackles and opponent contacts are a part of the game. However, volleyball players may be at risk for injuries due to sport-specific tasks, such as jumping and landing, as well as spiking and blocking the ball (14). Two prospective one-season cohort studies from national divisions in the Netherlands and Norway have reported an incidence of one to two injuries per 1000 training hours and three to four injuries per 1000 playing hours during competitions $(15,16)$. Studies in volleyball have been more retrospective. Therefore, in order to obtain injury information more precisely, it is necessary to have prospective studies that pay special attention to the types of injuries caused by overtraining, sex, and level 
of play, timing and injury costs. These cases are rarely studied with adequate details and design studies. Therefore, they need further researches. Although all injuries cannot be prevented, preventing even one injury can improve the performance and physical condition of an athlete. Considering that FMS cannot be anticipated to fully represent the movement patterns achieved in sports, and also because its ability to predict injury in sports populations is still in doubt, therefore the researcher has come to the conclusion that provides a functional screening tool that can predict injury in volleyball sports. For this purpose, by reviewing the literature on the background of injuries and taking into account their prevalence, as well as the types of movement patterns and performance requirements of volleyball players, a questionnaire consisting of 82 tests in the six categories of functional testing, agility, aerobic, anaerobic, muscle length and anthropometric was designed, and through interviews with volleyball experts such as coaches, physicians and physiotherapists, initial tests were conducted for the inclusion of the tools. Subsequently, with a quantitative study of validity and reliability of these tests, a final tool was developed in the form of a questionnaire.

\section{MATERIALS AND METHODS}

Design. This descriptive qualitative study, carried out in 2017, used semi-structured interviews to collect data (see Diagram 1).

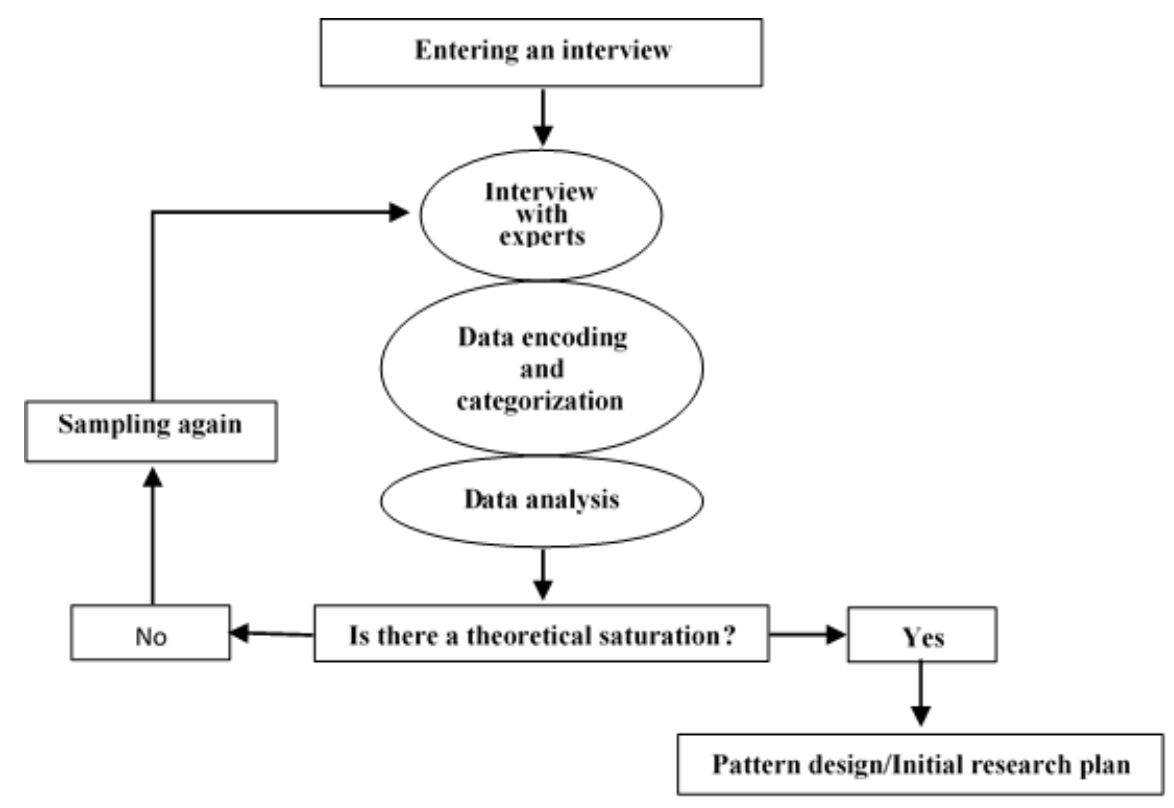

Diagram 1. Interview steps and initial research plan/pattern design.

Participants. The statistical population in this study included all experts in the field of volleyball, including coaches, instructors, and sports physiotherapists. The number of interviewees (sample size) depended on the theoretical saturation of the questions (17). In this study, data were saturated with 20 interviews, and so the interview process ended. The place of research was mainly the Iran volleyball federation, and some interviews were held at volleyball academies.
Data Collection. Individual semi-structured interviews were conducted to collect the data. The interviews began with an informal talk to ensure that a conversation occurred between the researcher and the participants, and the participants were assured that confidentiality would be maintained. Subsequently, an openended question was asked. Based on the interviewees' responses, follow- up questions were asked to clarify the concept of the study (for instance, "Can you explain more?" or "Can you 
provide an example?"). The analysis of the data collected from each interview directed the next interview. The sampling continued till the data were saturated, and thus 20 interviewees were included in the study. Each interview lasted for 60-120 min, with an average of $80 \mathrm{~min}$. The data were collected in 2017.

Data Analysis. All the interviews were conducted by a researcher and each was transcribed verbatim after recording. Then, the transcripts were read several times while listening to the recorded voices for immersing oneself in the data. Subsequently, each transcript was imported into MAXQDA 10 software ${ }^{\circledR}$ to organize and categorize the information provided by the experts as well as to analyze the content of the interviews.

Rigor. To ensure rigor in the study, Guba and Lincoln's (1989) assessment criteria were used. Prolonged engagement with the data, member checks and data triangulation with the maximum variation in sampling were ensured. The conformability of the findings was assessed by two external experts who were familiar with the qualitative research.

Ethical Considerations. The sampling process was carried out after receiving approval from the Local Ethical Committee and a referral from the University of Guilan to enter the research context. The ethical principles of seeking informed agreement from the participants and ensuring the confidentiality of their personal information were followed. The location and date of the interviews were determined based on the participants' agreement. This research was also done under the supervision of Iran volleyball federation.

\section{RESULTS}

The participants in the present study included 20 volleyball experts. The experts' ages ranged between 39 and 59 years and their mean age was 46 (SD 5.88). Other demographic features are listed in Table 1.

Table 1. Demographic features of participants $(N=20)$

\begin{tabular}{|c|c|c|}
\hline Variable & $\mathbf{N}$ & $\%$ \\
\hline \multicolumn{3}{|c|}{ Gender } \\
\hline Male & 16 & 80 \\
\hline Female & 4 & 20 \\
\hline \multicolumn{3}{|c|}{ Education } \\
\hline $\mathrm{BSc}$ & 4 & 20 \\
\hline MSc & 10 & 50 \\
\hline PHD & 6 & 30 \\
\hline \multicolumn{3}{|c|}{ History of education } \\
\hline to 5 years & 2 & 10 \\
\hline 5 to 10 years & 8 & 40 \\
\hline Up to 10 years & 10 & 50 \\
\hline
\end{tabular}

The results of the interviews were analyzed for determining the tests that were eligible for the tool. During the process of analysis, initial codes were extracted and finally, 38 of the 82 existing potential tests were identified. Table 2 lists the extracted codes in the framework analysis process. After analyzing the framework process for the six main items, 38 sub-items were identified. Then, through different stages of determining validity and reliability, 12 tests were identified for inclusion in the tool (Table 3).

\section{DISCUSSION}

Recently, researchers have used the Functional Movement Screening Tool designed by Gray Cook et al. as a predictor of injuries in sports. However, there is little evidence to support the comprehensiveness of FMS tests and their relationship to screening tools in sports populations. It seems that FMS has not been aware of and neglected the component of speed. Dynamic movements performed at high speed, which are the intrinsic variables of any sport, are ignored in this tool. Therefore, FMS 
seems to be unable to fully provide functional movement patterns in sports (18). This was supported by Parchmann and McBride (2011). They compared FMS and 1RM back squat and their relationship with a sprint of $10.20 \mathrm{~m}$, jump height and agility t-test in 25 NCAA division 1 golfers. The lack of correlation between FMS and these performance tests confirmed that FMS has limited ability to predict physical performance evaluations of acceleration, power, and agility, especially when it compared lower extremity power (6).

Table 2. List of extracted codes after analyzing the results of the interviews

\begin{tabular}{cl}
\hline Main item & Sub items \\
\hline Functional tests & $\begin{array}{l}\text { Deep squat, functional reach, single leg squat, triple hop for distance, hexagon, in line } \\
\text { lunge, trunk stability push up, Y balance, star excursion balance, multiple single leg } \\
\text { hop stabilization, rotary stability, vertical jump, carioca drill, lateral lunge, timed sit } \\
\text { up, supine bridge, shoulder mobility, active knee extension, 4 square step, endurance } \\
\text { of lateral flexors, single leg landing, active straight leg raise, triple jump for distance, } \\
\text { backward overhead medicine ball throw, sidearm medicine ball throw, closed kinetic } \\
\text { chain upper extremity }\end{array}$ \\
\hline Agility tests & T test, Illinois, zigzag run \\
\hline Anaerobic tests & Jump squat \\
\hline Aerobic tests & None \\
\hline $\begin{array}{c}\text { Muscle length } \\
\text { tests }\end{array}$ & $\begin{array}{l}\text { Lumbar erector spinae assessment, quadratus lumbar assessment, Thomas test, } \\
\text { pectoralis major assessment, pectoralis minor assessment, latissimus dorsi assessment }\end{array}$ \\
\hline $\begin{array}{c}\text { Anthropometric } \\
\text { tests }\end{array}$ & Arm span, arm reach \\
\hline
\end{tabular}

Table 3. Final codes after completing the different stages of validity and reliability

\begin{tabular}{ccc}
\hline Main item & \multicolumn{2}{c}{ Sub items } \\
\hline Functional tests & $\begin{array}{l}\text { Deep squat, triple hop for distance, hexagon, in line lunge, trunk stability push up, rotary } \\
\text { stability, lateral lunge, shoulder mobility, triple jump for distance, sidearm medicine ball } \\
\text { throw, closed kinetic chain upper extremity }\end{array}$ \\
\hline Agility tests & none \\
\hline Anaerobic tests & Jump squat \\
\hline Aerobic tests & None \\
\hline $\begin{array}{c}\text { Muscle length } \\
\text { tests }\end{array}$ & None \\
\hline $\begin{array}{c}\text { Anthropometric } \\
\text { tests }\end{array}$ & None \\
\hline
\end{tabular}

To consider this issue, it seems reasonable to use tools that measure the speed component in assessing the movement abilities of athletes. This may complement FMS, thereby providing a better picture. Velocity-based tests such as the landing error scoring system (LESS), squat jump (SJ) and single leg landing (SLL) have long been included in fitness testing batteries, but not always for movement screening purposes. In this regard, similar assessment has been used to identify the risk factors for injuries (7).

Chorba et al. evaluated FMS's ability to determine the risk of injury in 38 female collegiate athletes. Seven of the 38 reported prior reconstructive surgery on their anterior cruciate ligament (ACL), and $69 \%$ of the subjects with an FMS score of less than 14 were exposed to at least one injury during the pre-season treatment interventions. On the other hand, there was a high correlation $(\mathrm{R}=.76)$ between the low-scoring subjects on FMS and injury rates. Though, what is perhaps more important in this study was that FMS was not able to discriminate between the subjects with and without ACL injury history (19). Since previous ACL injury can lead to a change in the functional movement pattern, 
inability to differentiate between athletes with and without ACL injury can lead to the risk of reinjury in athletes with a history of ACL injury (20). This is an issue that FMS has not addressed. The probable outcome of this study is that due to the fact that the static components of FMS tests are more than their dynamic components, they are not sufficiently capable of identifying functional limitations in athletes with previous history of injury. Therefore, there is a need for different forms of dynamic assessments that reflect the speed and power of various sports movements. Keeping this in mind, it seems that in order to increase the ability of FMS to identify the risk factors for injury, emphasis should be on the necessity of complete performance tests based on dynamic stability in that tool.

Therefore, in the present study, the researcher sought to select the tests that could identify the potential risk factors for volleyball injuries through interviews with volleyball experts.

Based on the interviews with experts for this study, out of the 82 tests related to screening of functional movements, 38 tests were selected in the preliminary screening that included 26 functional tests, three agility tests, one anaerobic test, six muscle length tests and two anthropometric tests. None of the aerobic tests were selected by the experts. The reason was that aerobic exercises are less frequent in volleyball and the aerobic system of volleyball players can be strengthened by increasing the training duration. The other reason was that aerobic tests are time-consuming, and so they cannot fit into the tools. Furthermore, aerobic activities can be assumed as an indirect risk factor for injuries. In other words, fatigue, which is related to aerobic activities, may lead to injuries in athletes. A screening tool should be simple and have the ability to run in a timely manner. Finally, by determining the validity and reliability, 12 tests were identified. Of these, five tests involving deep squat, inline lunge, trunk stability push up, rotary stability and shoulder mobility are common with FMS. Seven other tests, including triple hop for distance, hexagon, lateral lunge, triple jump for distance, sidearm medicine ball throw, closed kinetic chain upper extremity and squat jump, were selected for placement in the final screening tool. Six of these seven tests were in the category of functional tests, and only one of them, squat jump, was part of the anaerobic test. Regarding the chosen tests, it can be seen that they can largely cover for the drawbacks of FMS. These tests, with rapid decelerations and high eccentric force and by challenging dynamic speed and stability, are capable of locating the athlete in situations of asymmetry and limitation, thereby identifying the stability and mobility dysfunctions that are predictors of injuries in sports. It seems that the selection of tests is closer to the common movement patterns in volleyball and the anatomical areas that are susceptible to injuries in this sport. Considering that acute ankle sprain, patellar tendinopathies, shoulder pain and back injuries in volleyball are most common (14), the focus of the experts was to select the tests aiming to prevent these injuries.

\section{CONCLUSION}

The study sought to provide a standardized applied method for movement-based assessment in the field of rehabilitation and physical fitness in volleyball, and thus provided an opportunity for those working in this field to deal with the potential risks of injury and other disorders, and help them to get better diagnosis. More prospective and follow up studies are needed to show the capability of these tests to predict injuries in future.

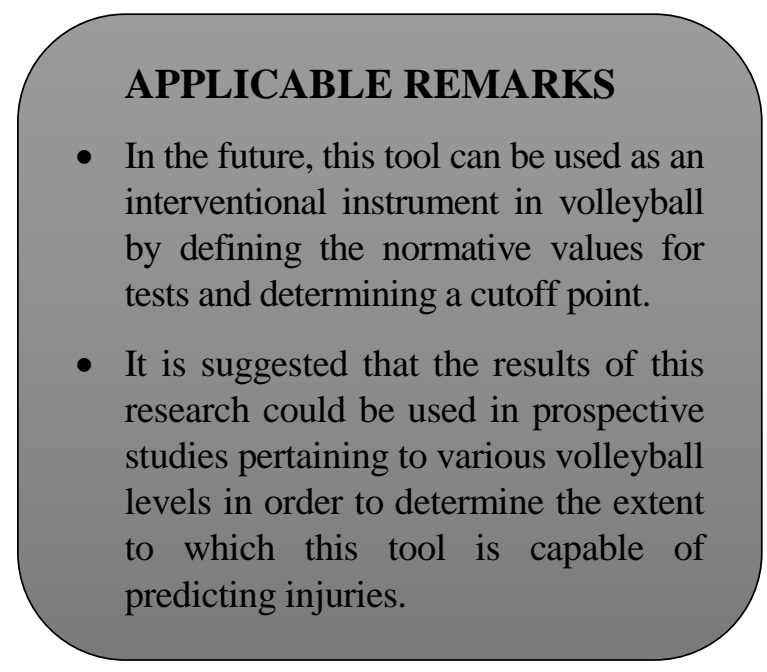

\section{ACKNOWLEDGEMENTS}

This study is part of a doctoral thesis by the first author of the article, and it was conducted by the Faculty of Sports Sciences and Physical Education of the University of Guilan. We 
would like to express our deepest appreciation to the Volleyball Federation Education Committee, which issued the license for this study. We also appreciate the help by experts who shared their personal experiences for this research.

\section{REFERENCES}

1. Cook G, Burton L, Hoogenboom BJ, Voight M. Functional movement screening: the use of fundamental movements as an assessment of function-part 1. International journal of sports physical therapy. 2014;9(3):396.

2. Kiesel K, Plisky PJ, Voight ML. Can serious injury in professional football be predicted by a preseason functional movement screen? North American journal of sports physical therapy: NAJSPT. 2007;2(3):147.

3. Dorrel BS, Long T, Shaffer S, Myer GD. Evaluation of the functional movement screen as an injury prediction tool among active adult populations: a systematic review and meta-analysis. Sports health. 2015;7(6):532-7.

4. Warren M, Smith CA, Chimera NJ. Association of the functional movement screen with injuries in division I athletes. Journal of sport rehabilitation. 2015;24(2):163-70.

5. Bishop C, Read P, Walker S, Turner AN. Assessing movement using a variety of screening tests. Professional Strength \& Conditioning. 2015(37):17-26.

6. Parchmann CJ, McBride JM. Relationship between functional movement screen and athletic performance. The Journal of Strength \& Conditioning Research. 2011;25(12):3378-84.

7. Bishop C. Movement screening: An integrated approach to assessing movement quality. Advanced Strength and Conditioning: An Evidence-based Approach. 2017.

8. Mottram S, Comerford M. A new perspective on risk assessment. Physical Therapy in Sport. 2008;9(1):40-51.

9. Dallinga JM, Benjaminse A, Lemmink KA. Which screening tools can predict injury to the lower extremities in team sports? Sports medicine. 2012;42(9):791-815.

10. Morehead EK. Development of a Functional Movement Screening Tool for Football: University of Central Lancashire; 2014.

11. Sleeper MD, Kenyon LK, Casey E. Measuring fitness in female gymnasts: the gymnastics functional measurement tool. International journal of sports physical therapy. 2012;7(2):124.

12. Gabbe BJ, Finch CF, Wajswelner H, Bennell KL. Predictors of lower extremity injuries at the community level of Australian football. Clinical journal of sport medicine. 2004;14(2):56-63.

13. Steinberg N, Hershkovitz I, Peleg S, Dar G, Masharawi Y, Heim M, et al. Range of joint movement in female dancers and nondancers aged 8 to 16 years: anatomical and clinical implications. The American journal of sports medicine. 2006;34(5):814-23.

14. Bere T, Kruczynski J, Veintimilla N, Hamu Y, Bahr R. Injury risk is low among world-class volleyball players: 4year data from the FIVB Injury Surveillance System. British journal of sports medicine. 2015:bjsports-2015094959.

15. Verhagen E, Van der Beek AJ, Bouter LM, Bahr R, Van Mechelen W. A one season prospective cohort study of volleyball injuries. British journal of sports medicine. 2004;38(4):477-81.

16. Bahr R, Bahr I. Incidence of acute volleyball injuries: a prospective cohort study of injury mechanisms and risk factors. Scandinavian journal of medicine \& science in sports. 1997;7(3):166-71.

17. Corbin J, Strauss A, Strauss AL. Basics of qualitative research: Sage; 2014.

18. Agbese OO. Examining the relationship between functional movement screen (FMS) and computerized BESS scores and lower extremity injury risk in a cohort of female intercollegiate athletes: University of Delaware; 2016.

19. Chorba RS, Chorba DJ, Bouillon LE, Overmyer CA, Landis JA. Use of a functional movement screening tool to determine injury risk in female collegiate athletes. North American journal of sports physical therapy: NAJSPT. 2010;5(2):47.

20. Georgoulis AD, Ristanis S, Chouliaras V, Moraiti C, Stergiou N. Tibial rotation is not restored after ACL reconstruction with a hamstring graft. Clinical Orthopaedics and Related Research®. 2007;454:89-94. 